\title{
XXXII. On the instability of gaseous jets
}

\author{
Joseph H.T. Roberts M.Sc. \& E. Meigh M.Sc.
}

To cite this article: Joseph H.T. Roberts M.Sc. \& E. Meigh M.Sc. (1912) XXXII. On the instability of gaseous jets, Philosophical Magazine Series 6, 23:135, 368-375, DOI: 10.1080/14786440308637230

To link to this article: http://dx.doi.org/10.1080/14786440308637230

曲 Published online: 08 Jun 2010.

Submit your article to this journal $\pi$

Џ Article views: 2

Q View related articles $\sqsubset$

4 Citing articles: 1 View citing articles 


\section{[ 368 ]}

XXXII. On the Instability of Gaseous Jets. By JosePH H. T. RoberTs, M.Sce, and E. MeIGH, M.Sc., University of Liverpool *.

A $S$ a result of some experiments on the flow of gases A through tubes, the writers were led to consider how the phenomena of flow would be modified as the tubes were made shorter and shorter, until they ultimately approximated to holes in infinitely thin plates. It is well known that if the pressure causing a gas to flow through an orifice into an atmosphere be increased beyond a certain critical value the flow becomes irregular, and also that under certain circumstances the gaseous jet may exhibit a sensitiveness to sonorous vibrations, a familiar example of such sensitiveness being that of the sensitive gas-flame. Most experimenters upon sensitive flames appear to have used the pin-hole steatite burner, or a drawn-out glass tube, but there is reason to believe that greater sensitiveness can in general be obtained with jets from holes in very thin plates, and these jets are more immune from the influence of disturbances other than ; onorcus vibrations.

The instability or sensitiveness of a jet depends upon the vorticity. Before proceeding to describe experiments upon jets, it will be well to discuss the theory $t$, and to see what a priori reason there is to expect that the jet from a tube will, in general, be more stable than one from a hole in a thin plate.

"In the ideal case of abrupt transitions of velocity, constituting vortex sheets, in frictionless fluid, the motion is always unstable, and the degree of instability increases as the wavelength of the disturbance diminishes.

"The direct application of this result to actual jets would lead us to the conclusion that their sensitiveness increases indefnitely with pitch. It is true that, in the case of certain flames, the pitch of the most efficient sounds is very high, not far from the upper limit of human hearing; but there are other kinds of sensitive jets on which these high sounds are without effect, and which require for their excitation a moderate, or even a grave pitch.

"A probable explanation of the discrepancy readily suggests itself. The calculations are founded upon the supposition that the changes of velocity are discontinuous-a supposition that cannot possibly agree with reality. In consequence of fuid friction, a surface of discontinuity, even if it could ever

* Communicated by the Authors.

+ Rayleigh, 'Sound,' vol. ii. ch. xxi. 
be formed, would instantaneously disappear, the transition from the one velocity to the other becoming more and more gradual, until the layer of transition attained a sensible width. When this width is comparable with the wave-length of a sinuous disturbance, the solution for an abrupt transition ceases to be applicable, and we have no reason for supposing that the instability would increase for much shorter wave-lengths.

"There is, therefore, ample foundation for the suspicion that the phenomena of sensitive jets may be greatly influenced by fluid friction, and deviate materially from the results of calculations based upon the supposition of discontinuous changes of velocity. Under these circumstances it becomes important to investigate the character of the equilibrium of stratified motion.

"The manner in which viscosity operates is probably as follows. At the root of the jet, just after it issues from the nozzle, there is a rear approach to discontinuous motion, and a high degree of instability. If a disturbance of sufficient intensity and of suitable period have access, the regular motion is lost, and cannot afterwards be recovered. But the instability bas a very short time in which to produce its effect. Under the influence of viscosity the changes of velocity become more gradual, and the instability decreases rapidly, if it does not disappear altogether. Thas if the dis. turbance be insufficient to cause disintegration during the brief period of instability, the jet may behave very much as though it had not been disturbed at all, and may reach the full development observed in long flames and smoke-jets."

It would thus appear that in genernl, an orifice of tubular form would tend to increase the discrepancy between theory and practice, by communicating to the jet a stratified formation, and thus lowering the pitch of the disturbances to which it was sensitive, or reducing the sensitiveness altogether, while a thin-plate orifice might be expected to give, near the root of the jet, an approximation to discontinuous ehanges of velocity, and consequently a considerable degree of sensitiveness for disturbances of high pitch.

The apparatus used in these experiments consisted of weighted gas-bags; a speci:l gas-meter reading $1 \mathrm{cu}$. $\mathrm{ft}$. per rev., the dial being divided into 100 parts; a watermanometer attached about 2 inches below the orifice; and a number of orifices consisting of holes in thin circular plates of copper and platinum, the plates being secured in an annular screw-head holder, and of tubes, and holes in thick plates.

Phil. Mag. S. 6. Vol, 23. No. 135. Mareh 1912. 2 C 
The greatest difficulty met with in these experiments is that the pressure necessary to produce flaring, or to bring a jet to its condition of maximum sensitiveness, is very much influenced by accidental irregularities in the orifice. Two orifices, identical in dimensions and method of manufacture, might be expected to give flames with identical properties, but this is far from being the case. So important are small irregularities in the rim, that an orifice which appeared perfect when viewed through a powerful microscope would produce variations of as much as 20 per cent. or 30 per cent. in, say, the flaring-pressures of the jets from its two surfaces. The quantities in the jet cannot be considered to be functions of the measurable dimensions of the orifice unless the jets from opposite surfaces are identical. We have never succeeded in securing the complete fulfilment of the latter condition, but the approximation depends upon the method of manufacturing the orifices. After trying a variety of ways, the method we found most successful was to grip the disk of metal (about $0.15 \mathrm{~mm}$. thickness) between the convex cheeks of two curved pieces of hard brass strip, and to bore the hole with a lathe twist-drill through all three.

Various sources of sound were used to test the sensitiveness of the flames, including bird-calls, whistles, pipes, and vibrating bars. The sounds which affect these flames are all of very high pitch ; as a general rule we found the sensitiveness to increase with the diameter of the orifice, but in the case of orifices above $2 \mathrm{~mm}$. diam. the flames were very long and somewhat inconvenient. On one occasion, with an orifice $1.107 \mathrm{~mm}$. diam., we obtained a flame which, without the aid of resonators, was practically as sensitive as the ear itself. It responded to a whistle at the opposite end of the building, and when the flame ceased to respond it was almost impossible to tell, by ear, whether the whistle was sounding or not.

Some results of observations on the jets from holes in thin plates are given in the following table; the minimum sensitiveness pressure is an arbitrary quantity, depending upon the pitch and intensity of the disturbing note.

It will be seen from the table that there is a considerable range of pressure over which the jet is sensitive, the development of sensitiveness with increase of pressure being very gradual. It should be mentioned that jets from very small holes in thin plates (about $0.3 \mathrm{~mm}$. diam.) required about $80 \mathrm{~cm}$. of water to make them flare, and did not exhibit any sensitiveness. 


\section{TABLE I.}

Holes in thin plates. Thickness of plates $0.15 \mathrm{~mm}$.

\begin{tabular}{|c|c|c|c|c|c|c|}
\hline \multirow{2}{*}{$\begin{array}{l}\text { Diam. of Orifice } \\
\text { in } \mathrm{mm} \text {. }\end{array}$} & \multicolumn{3}{|c|}{$\begin{array}{l}\text { Mean pressure in } \mathrm{cm} \text {, of } \\
\text { water required for }\end{array}$} & \multicolumn{3}{|c|}{$\begin{array}{l}\text { Mean length }(\mathrm{cm} .) \\
\text { of flame when }\end{array}$} \\
\hline & Flaring. & $\begin{array}{c}\text { Maximum } \\
\text { Sensitive- } \\
\text { ness. }\end{array}$ & $\begin{array}{c}\text { Minimum } \\
\text { Sensitive- } \\
\text { ness. }\end{array}$ & Flaring. & $\begin{array}{l}\text { Max. } \\
\text { Sens. }\end{array}$ & $\begin{array}{l}\text { Min. } \\
\text { Sens. }\end{array}$ \\
\hline $0 \cdot t) 19$ & $31 \cdot 3$ & $30 \cdot 6$ & $16 \cdot 0$ & $19 \cdot 5$ & $21 \cdot 0$ & 138 \\
\hline 0.643 & $39 \cdot 0$ & 360 & $19 \cdot 0$ & $20 \cdot 5$ & $23 \cdot 5$ & $17 \cdot 5$ \\
\hline 0.719 & $36 \overline{5}$ & 320 & $18 \cdot 0$ & $22 \cdot 0$ & 250 & 190 \\
\hline 0.905 & $36 \cdot 0$ & $33 \cdot 0$ & $17 \cdot 5$ & $37 \cdot 0$ & $41 \cdot 0$ & $29 \cdot 0$ \\
\hline $1 \cdot 107$ & $34 \cdot 0$ & $33 \cdot 0$ & 230 & $38 \cdot 0$ & 520 & $42 \cdot 0$ \\
\hline $1 \cdot 30$ & 1266 & $11 \cdot 6$ & 60 & $38 \cdot 5$ & 540 & $37 \cdot 0$ \\
\hline $2 \cdot 0$ & $10 \cdot 0$ & $9 \cdot 0$ & $4 \cdot 0$ & $35 \cdot 0$ & 600 & 450 \\
\hline $3 \cdot 0$ & 50 & 4.0 & $2 \cdot 7$ & $50 \cdot 0$ & $65 \cdot 0$ & $60 \cdot 0$ \\
\hline
\end{tabular}

Experiments were then made with jets from narrow glass tubes; a number of obserrations are given in the following table. It will be seen that the range of pressure for sensitiveness is extremely small, in some cases the numbers in columns 4 and 6 being the same. A remarkable feature of the jets from tubes is the extreme suddenness of the transition from a condition of stability to one of flaring; in some cases the slightest touch with the finger upon a large gasbag would be sufficient to bring the flame from the one condition to the other.

In place of short tubes, in which the irregularity of the ends would probably have produced considerable effect, we used thick-plate orifices, and it is interesting to observe, in Table II. (p.372), that as the diameter increases, that is as the length becomes less important, the sensitiveness begins to show itself. The flaring-pressure for a constant diameter decreases with the length in the case of every tube in Table II., but it increases with the thick-plate orifices. (Compare the following, Table II. tube no. 3, thick-plate no. 2, Table I. orifice no. 5.)

It thus appears that any tubularity of the orifice from which the jet issues, in general lowers the flaring-pressure and diminishes the sensitiveness for notes of high pitch; $2 \mathrm{C} 2$ 
while the flames from holes in very thin plates combine great sensitiveness to sonorous vibrations of high pitch with considerable immunity from the influence of disturbances of other kinds.

\section{TABLE II.}

\begin{tabular}{|c|c|c|c|c|c|}
\hline $\begin{array}{l}\text { Diam. of tube } \\
\text { in } \mathrm{mm} .\end{array}$ & $\begin{array}{c}\text { Lengt.b } \\
\text { (cul.) }\end{array}$ & $\begin{array}{l}\text { Flaring } \\
\text { Press. in } \\
\text { cm. of } \\
\text { water. }\end{array}$ & $\begin{array}{c}\text { Maximum } \\
\text { Sensitire- } \\
\text { ness Press. } \\
\text { (cm. of } \\
\text { water). }\end{array}$ & $\begin{array}{c}\text { Degree } \\
\text { of } \\
\text { Sensitiveness. }\end{array}$ & $\begin{array}{c}\text { Pressure at } \\
\text { which Sensi- } \\
\text { tiveness } \\
\text { disappears. }\end{array}$ \\
\hline 0.7238 & $\begin{array}{l}6 \cdot 25 \\
3 \cdot 6 \\
2 \cdot 4 \\
1 \cdot 4\end{array}$ & $\begin{array}{l}62 \cdot 0 \\
34 \cdot 0 \\
32 \cdot 0 \\
20 \cdot 0\end{array}$ & & & \\
\hline 0.9811 & $\begin{array}{l}6 \cdot 9 \\
4 \cdot 6 \\
2 \cdot 5\end{array}$ & $\begin{array}{l}27 \cdot 0 \\
20 \cdot 0 \\
12 \cdot 0\end{array}$ & & & \\
\hline $1 \cdot 133$ & $\begin{array}{l}9 \cdot 75 \\
5 \cdot 55 \\
3 \cdot 2 \\
1.6 \\
0.9\end{array}$ & $\begin{array}{r}21 \cdot 0 \\
160 \\
90 \\
70 \\
4 \cdot 0\end{array}$ & $\begin{array}{r}16 \\
7\end{array}$ & $\begin{array}{l}\text { Minute. } \\
\text { Minute. }\end{array}$ & $\begin{array}{r}16 \\
7\end{array}$ \\
\hline $1 \cdot 666$ & $\begin{array}{l}5 \cdot 85 \\
3.55 \\
288 \\
1 \cdot 6\end{array}$ & $\begin{array}{l}6.6 \\
50 \\
50 \\
3 \cdot 6\end{array}$ & $\begin{array}{l}6 \cdot 5 \\
4 \cdot 9 \mathbf{5} \\
4 \cdot 95 \\
3 \cdot 6\end{array}$ & $\begin{array}{c}\text { Slight. } \\
", \\
"\end{array}$ & $\begin{array}{l}5 \cdot 5 \\
4 \cdot 90 \\
4 \cdot 80 \\
3 \cdot 6\end{array}$ \\
\hline $2 \cdot 381$ & $\begin{array}{l}5 \cdot 1 \\
3 \cdot 92 \\
2 \cdot 23 \\
1 \cdot 33\end{array}$ & $\begin{array}{l}2 \cdot 2 \\
2 \cdot 0 \\
1 \cdot 4 \\
1 \cdot 0\end{array}$ & $\begin{array}{l}2 \cdot 0 \\
2 \cdot 0 \\
1 \cdot 4\end{array}$ & $\begin{array}{l}\text { Slight. } \\
\text { Moderate. } \\
y\end{array}$ & $\begin{array}{l}20 \\
20 \\
1 \cdot 4\end{array}$ \\
\hline $1 \cdot 054$ & $\begin{array}{l}\text { T'bick } \\
0.629\end{array}$ & $\begin{array}{l}\text { plate } \\
9 \cdot 4\end{array}$ & $9 \cdot 0$ & Considerable. & $8 \cdot 7$ \\
\hline $1 \cdot 140$ & $\begin{array}{l}\text { Thick } \\
0.313\end{array}$ & $\begin{array}{l}\text { plate } \\
10^{-4}\end{array}$ & $10 \cdot 0$ & Considerable. & $9 \cdot 4$ \\
\hline
\end{tabular}

In Table I. it will be noticed that the flaring-pressures for the first five orifices are not greatly different, but that there is a drop in the flaring-pressure when the diameter becomes greater than, say, $1.2 \mathrm{~mm}$. This would seem to indicate that over a certain range of diameters of orifice the flaring depends simply on what might be called the linear velocity of flow at the orifice. With a view to testing this point we 
made a number of determinations of volumetric rates of low, through the gas-meter. In Table III. are given the diameters, flaring-pressures, and volumetric rates of flow; the

T'ABLE III.

\begin{tabular}{|c|c|c|c|}
\hline $\begin{array}{c}\text { Diam. of } \\
\text { Oritice in mn. }\end{array}$ & $\begin{array}{c}\text { Flaring Press. } \\
\text { in cm. water. }\end{array}$ & $\begin{array}{c}\text { Amount passed } \\
\text { per sec. when } \\
\text { flaring, in } \\
\text { cubic inches. }\end{array}$ & $\begin{array}{c}\text { Linear Velocity } \\
\text { of Flow } \\
\times \text { Constant. }\end{array}$ \\
\hline 0.619 & 31.0 & $1 \cdot 152$ & 3006 \\
0.643 & 37.6 & 1.271 & 3073 \\
1.100 & 37.0 & 3.756 & 3103 \\
1.107 & 35.4 & 3.526 & 2914 \\
1.30 & 13.4 & 2.879 & 1704 \\
2.00 & 9.8 & $5 \cdot 759$ & 1440 \\
3.00 & 58 & 10.06 & 1129 \\
\hline
\end{tabular}

quantity in the last column, called linear velocity, is obtained by dividing the volumetric rate of flow by the square of the diameter of the orifice.

It is seen that the numbers in the last column show the same sudden drop as the flaring-pressures in Table I.

We have also made observations on the relation between pressure and rate of flow, with a given orifice, for ignited and unignited jets, and have found in every case that the rate of flow for a given pressure is greater for an unignited than for an ignited jet. "When a flame is lighted at the burner there are further complications, of which it is difficult to give an adequate explanation. The high temperature leads indeed to increased viscosity, and this tends to explain the higher pressures then admissible, and the graver notes which then become operative. But it is probable that the change due to ignition is of a still more fundamental nature" *.

The figure shows how the curve for the ignited jet lies below that for the unignited jet. $P$ is the pressure in $\mathrm{cm}$. of water and $\mathrm{V}$ is the volumetric rate of flow in cubic feet per second.

* Rayleigh, 'Sound,' vol. ii. p. 409. 


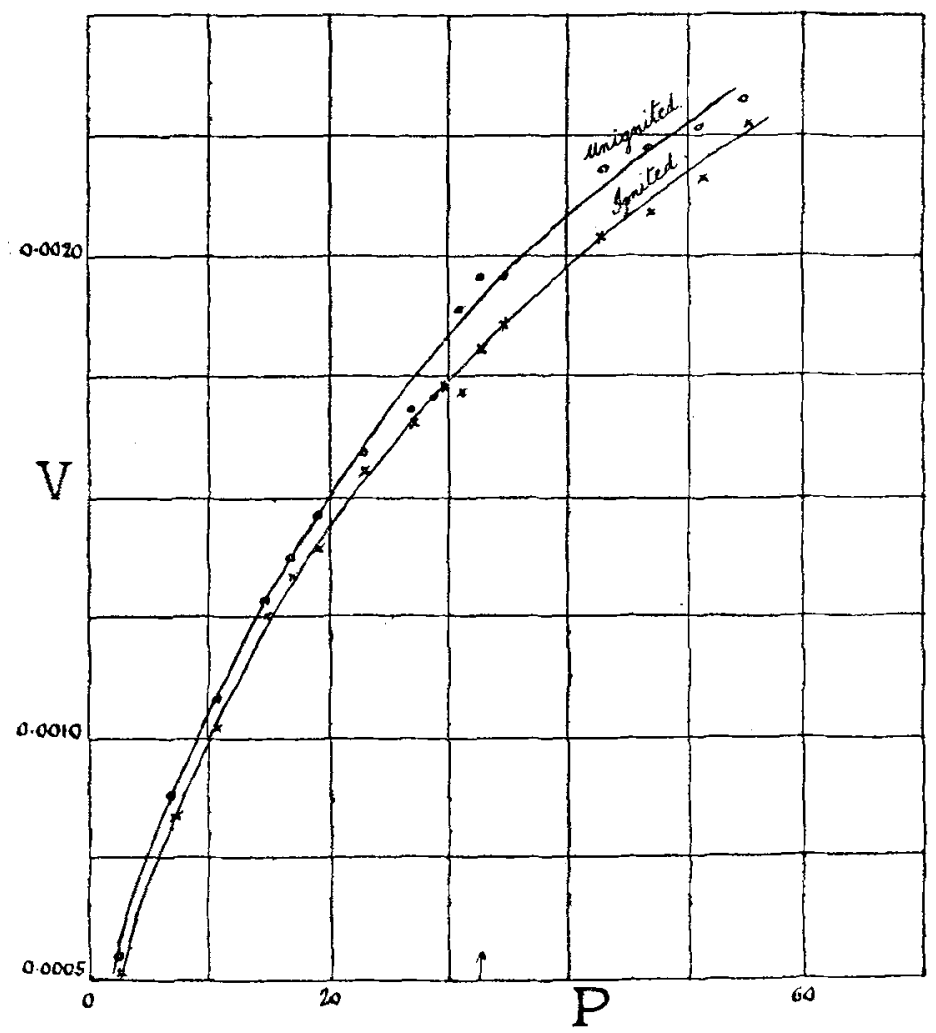

In the upper curve there is great irregularity in the neighbourhood of the flaring-pressure; this appeared in all the curves. The flaring-pressure is shown by the arrow in the curve.

\section{Conclusion.}

The instability of a jet depends upon the vorticity at its surface. Any tubularity of the orifice from which the jet issues communicates stratified formation to the jet, and thus, in general, lowers the pitch of the sonorous disturbances to which it is sensitive, and diminishes the sensitiveness. The flaring-pressures of the flames from holes in thin plates are very much higher than those of the flames from tubes; on this account the flames from the former orifices are long and stiff. The transition of velocity at the surface of such jets is sudden, the pitch of the sonorous disturbances to which the jets are sensitive is very high, and the sensitiveness is 
much greater than that of the jets from other orifices; in some cases the sensitiveness of a simple flame jet would approximate to that of the ear itself.

The flaring appears to depend, for a certain range of diameters of orifices, almost simply upon the linear rate of flow at the orifice. For diameters above this range, flaring occurs at much lower pressures.

The high temperature in ignited jets leads to increased viscosity, and this tends to explain the higher pressures then admissible. For a given pressure and orifice, the rate of flow is greater for an unignited than for an ignited jet.

In conclusion we wish to thank Professor Wilberforce for the keen interest which he has shown in these experiments.

George Holt Physics Laboratory, University of Liverpool.

XXXIII. Non-Neutonian Mechanics, The Mass of a Moving Body. By Righard C. Tolman, Ph.D., Assistant Professor of Physical Chemisiry at the University of Cincinnati*

A $\mathrm{N}$ acceptance of the Einstein theory of relativity necesA sitates a revision of the Newtonian system of mechanics. In making such a revision it is desirable to retain as many as possible of the simpler principles of Newtonian mechanics. Some of the consequences have already been presented $\dagger$ of a system of mechanics which retains the conservation laws of mass, energy, and momentum, and defines force as the rate of increase of momentum; but to agree with the theory of relativity introduces an idea foreign to Newtonian mechanies by considering that both the mass and velocity of a body are variable.

From the theory of relativity, Einstein has calculated both the transverse and the longitudinal accelerations experienced by a charged body moving in an electromagnetic field. On the basis of these accelerations, it has been usual to place the "transverse mass" of a body moving with the velocity $u$ as equal to $m_{0} / \sqrt{1-u^{2} / c^{2}}$, and its "longitudinal" mass as equal to $m_{0} /\left(1-u^{2} / c^{2}\right)^{\frac{3}{2}}$, where $m_{0}$ is the mass of the body at rest aud $c$ is the velocity of light. If, however, mass is a quantity to which a conservation law applies, the mass of a body cannot well be different in different directions; and

* Cumnunicated by the Author. Contribution from the Chemical Leiboratory of the University of Cincinnati.

+ Lewis, Phil. Mag. xvi. p. 705 (1908). Lewis \& Tolman, Phil. Mag. xvii. p. 510 (1909). Tolman, Phil. Mag. xxi. p. 296 (1911); xxii. p. 458 (1911). 